\title{
Adsorpsi Logam Tembaga (Cu), Besi (Fe), dan Nikel (Ni) dalam Limbah Cair Buatan Menggunakan Nanopartikel Cobalt Ferrite $\left(\mathrm{CoFe}_{2} \mathrm{O}_{4}\right)$
}

\author{
Femila Amor Nurdila ${ }^{1}$, Nining Sumawati Asri ${ }^{1}$, dan Edi Suharyadi* \\ ${ }^{1}$ Laboratorium Fisika Material dan Intrumentasi (Fismatel), Jurusan Fisika, Fakultas Matematika dan Ilmu Pengetahuan Alam, \\ Universitas Gadjah Mada, Yogyakarta, Indonesia \\ *Corresponding Author: esuharyadi@ugm.ac.id
}

\begin{abstract}
Abstrak - Nanopartikel $\mathrm{CoFe}_{2} \mathrm{O}_{4}$ telah berhasil disintesis menggunakan metode kopresipitasi dan digunakan sebagai adsorben untuk menurunkan kadar logam $\mathrm{Cu}, \mathrm{Fe}$, dan Ni dalam limbah cair buatan. Pengaruh suhu, lama pengadukan, readsorpsi dan pelapisan adsorben dengan Polyethylen glycol terhadap penurunan kadar logam telah dilakukan dalam penelitian ini. Prosentase penurunan kadar logam $\mathrm{Cu}, \mathrm{Fe}$, Ni diketahui meningkat dengan peningkatan suhu dan lama pengadukan namun tidak signifikan. Penurunan kadar logam maksimum untuk logam Cu dan Ni terjadi pada suhu $60^{\circ}$ C yaitu 99,70\% dan 99,94\%. Pengaruh lama pengadukan terhadap adsorpsi maksimum logam Cu pada 5 jam, sedangkan logam Ni terjadi pada 3 jam. Adsorpsi logam Fe tidak terpengaruh signifikan oleh perubahan suhu dan lama pengadukan. Peningkatan adsorpsi logam juga tampak saat dilakukan proses pengulangan (readsorpsi) namun ketika adsorben dilapisi dengan, Polyethylen glycol (PEG-4000) adsorpsi logam menurun. Hasil penilitian ini mengindikasikan bahwa $\mathrm{CoFe}_{2} \mathrm{O}_{4}$ dapat digunakan sebagai adsorben untuk menurunkan kadar logam $\mathrm{Cu}$, $\mathrm{Fe}$, dan Ni dalam limbah cair.
\end{abstract}

Kata kunci: nanopartikel, adsorpsi, ion logam, adsorben, $\mathrm{CoFe}_{2} \mathrm{O}_{4}$

\begin{abstract}
Cobalt Ferrite nanoparticles have been successfully synthesized using co-precipitation method and used for removal metals ions $\mathrm{Cu}, \mathrm{Fe}$, and $\mathrm{Ni}$ from artificial wastewater. The ability of removing metal ions using $\mathrm{CoFe}_{2} \mathrm{O}_{4}$ against temperature,contact time, re-adsorption and by addition of Polyethylene Glycol using a coating agent of adsorbent have been studied.The adorption process was found to be temperature dan contact time dependent but not significant. Maximum adsorption of 99,70\% for metal ions $\mathrm{Cu}$ and 99,94\% for metal ions $\mathrm{Ni}$ were observed at a temperature of $60^{\circ} \mathrm{C}$.

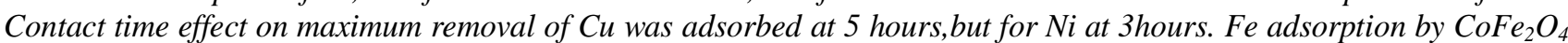
was found not significantly effected by temperature and contact time. The effectivity of adsorption by $\mathrm{CoFe}_{2} \mathrm{O}_{4}$ nanoparticles can be increased by readsorption, but the addition of adsorbent with Polyethylene Glycol resulted in the decrease of removing of metals ions. These results indicate that $\mathrm{CoFe}_{2} \mathrm{O}_{4}$ nanoparticles may be used as an adsorbent for removal of $\mathrm{Cu}, \mathrm{Fe}$, and $\mathrm{Ni}$ from wastewater.
\end{abstract}

Key words: nanoparticle, adsorption, metal ion, adsorbent, $\mathrm{CoFe}_{2} \mathrm{O}_{4}$

\section{PENDAHULUAN}

Penelitian nanoteknologi di bidang lingkungan khususnya penanggulangan pencemaran logam berat menaruh perhatian besar pada adsorben berbasis nanopartikel karena adsorben berbasis nanopartikel lebih murah dari sisi biaya, lebih efisien waktu, mudah diproduksi serta terbukti mampu menanggulangi pencemaran air oleh logam berat.

Adsorpsi merupakan metode yang efektif untuk mengatasi masalah pencemaran lingkungan. Metode adsorpsi bergantung pada kemampuan permukaan adsorben untuk menarik molekul-molekul gas, uap atau cairan. Berbagai jenis adsorben karbon aktif telah berhasil dikembangkan dan terbukti mampu mengadsorpsi ion logam berat, hanya saja tergolong mahal dan sulit untuk diproduksi ${ }^{[1]}$. Untuk itu, selama sepuluh tahun terakhir penelitian secara ekstensif diarahkan untuk mencari jenis adsorben yang relatif lebih murah dan mudah didapatkan.

Pemanfaatan adsorben nanopartikel magnetik $\mathrm{CoFe}_{2} \mathrm{O}_{4}$ dipilih karena memiliki keunggulan berupa sifat listrik dan kemagnetannya yang sangat baik sehingga dapat diaplikasikan dalam berbagai bidang. $\mathrm{CoFe}_{2} \mathrm{O}_{4}$ mempunyai sifat anisotropy magnetocrystalin cubic tinggi, koersivitas tinggi, dan magnetisasi saturasi yang sedang. Selain itu, $\mathrm{CoFe}_{2} \mathrm{O}_{4}$ memiliki konstanta anisotropi yang relatif tinggi $\left(290 \mathrm{~kJ} / \mathrm{m}^{3}\right)$ dan radius block superparamagnetik yang relatif besar $(13 \mathrm{~nm}$ pada suhu $300 \mathrm{~K})^{[2]}$.

Logam berat yang telah banyak diteliti antara lain logam $\mathrm{Sr}^{[3]}, \mathrm{Ur}^{[6]}, \mathrm{As}^{[4]}, \mathrm{Pb}^{[5]}$, dan $\mathrm{Hg}^{[5]}$ dan sebagian besar fokus pada mekanisme (interaksi oksidasi-reduksi) pada permukaan nanopartikel. Sedangkan logam seperti $\mathrm{Cu}, \mathrm{Fe}$, dan $\mathrm{Ni}$ sangat sedikit diteliti dan sangat sulit ditemukan di berbagai literatur. Pada penelitian ini, dilakukan proses adsorpsi logam $\mathrm{Cu}, \mathrm{Fe}$, dan $\mathrm{Ni}$ menggunakan adsorben nanopartikel $\mathrm{CoFe}_{2} \mathrm{O}_{4}$, di bawah pengaruh suhu, lama pengadukan, readsorpsi dan pelapisan adsorben menggunakan Polyethylene Glykol (PEG-4000) dengan perbandingan massa 1:1. 


\section{METODE PENELITIAN}

\section{A. Adsorben $\mathrm{CoFe}_{2} \mathrm{O}_{4}$}

Proses sintesis nanopartikel $\mathrm{CoFe}_{2} \mathrm{O}_{4}$ dilakukan dengan melarutkan $\mathrm{FeCl}_{3} \cdot 6 \mathrm{H}_{2} \mathrm{O}$ (ferric chloride hexahydrate) dan $\mathrm{CoCl}_{2} \cdot 6 \mathrm{H}_{2} \mathrm{O}$ (cobalt chloride hexa-hydrate). Setelah larut semua, selanjutnya larutan tersebut diteteskan ke dalam larutan $\mathrm{NaOH}$ secara perlahan dan diaduk di atas magnetik stirrer pada suhu $80{ }^{\circ} \mathrm{C}$ dengan kecepatan 450 rpm selama 3 jam. Larutan $\mathrm{CoFe}_{2} \mathrm{O}_{4}$ dicuci dengan aquades dan diendapkan. Endapan selanjutnya dikeringkan di dalam furnace pada suhu $80{ }^{\circ} \mathrm{C}$ (4 jam). Sampel yang kering kemudian dianalisis menggunakan Transmission Electron Microscopy, X-Ray Difraction, dan Fourier Transform Infra Red.

\section{B. Artificial Limbah Logam $\mathrm{Cu}, \mathrm{Fe}$, dan $\mathrm{Ni}$}

Proses pembuatan limbah buatan menggunakan bahan dasar $\mathrm{CuSO}_{4} \cdot 5 \mathrm{H}_{2} \mathrm{O}, \mathrm{FeSO}_{4} . \mathrm{H}_{2} \mathrm{O}$, dan $\mathrm{NiSO}_{4} .6 \mathrm{H}_{2} \mathrm{O}$ masing-masing 1,5 gram yang dilarutkan dalam $1000 \mathrm{~mL}$ aquades. Larutan diaduk menggunakan magnetic stirrer (suhu ruangan) selama 4 jam dengan ditambahkan $\mathrm{HCl}$ sebanyak 20 tetes. Selanjutnya, limbah buatan diuji menggunakan atomic absorption spectrophotometer (AAS).

\section{B. Serapan Logam $\mathrm{Cu}, \mathrm{Fe}$, dan $\mathrm{Ni}$}

Proses serapan logam dalam limbah cair buatandilakukan dengan melarutkan 0,4 gram $\mathrm{CoFe}_{2} \mathrm{O}_{4}$ kedalam $80 \mathrm{ml}$ limbah cair kemudian diaduk menggunakan magnetic stirrer. Laruran diberi $\mathrm{NH}_{4} \mathrm{OH}$ dengan kadar yang disesuaikan dengan kondisi $\mathrm{pH} 9$. Larutan yang terbentuk selanjutnya diaduk menggunakan magnetic stirrer (3 jam, suhu ruang). Larutan yang telah dipisahkan dari endapan disaring dengan kertas saring, kemudian dilakukan AAS. Untuk sampel dengan variasi suhu (RT, 60, 90, 120), lama pengadukan (1 jam, 3 jam, 5 jam), readsorpsi (pengulangan) dan $\mathrm{CoFe}_{2} \mathrm{O}_{4}+\mathrm{PEG}-4000$ dengan perbandingan 1:1. Selanjutnya, prosentase penurunan kadar logam dihitung dengan rumus berikut:

$$
\% \text { penurunan }=\frac{\text { kadar awal }- \text { kadar akhir }}{\text { kadar awal }} \times 100 \%
$$

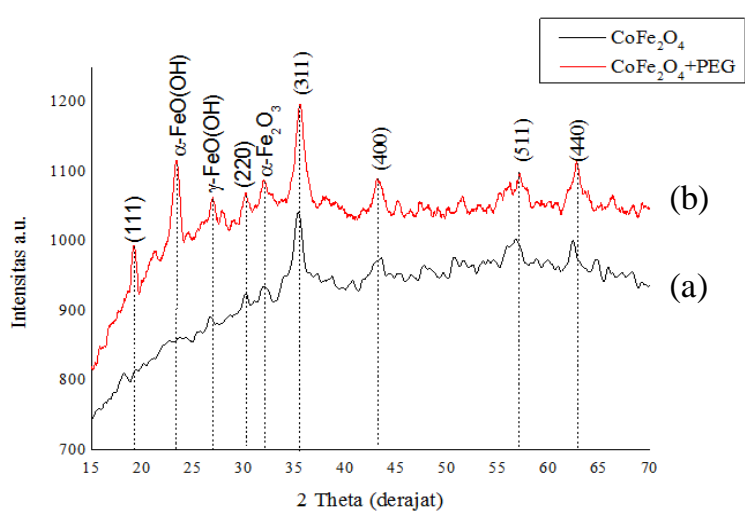

Gambar 1. Pola spektrum XRD; (a) $\mathrm{CoFe}_{2} \mathrm{O}_{4}$; (b) $\mathrm{CoFe}_{2} \mathrm{O}_{4}+$ PEG-4000

\section{HASIL DAN PEMBAHASAN}

\section{A. Karakterisasi Adsorben}

Hasil XRD pada gambar 1 menunjukkan indikasi terbentuknya fasa $\mathrm{CoFe}_{2} \mathrm{O}_{4}$ pada sampel. Indikasi tersebut didasarkan pada nilai parameter kekisi yang diestimasi dari sudut $2 \theta=35,379^{\circ}$ yaitu pada puncak utama dengan indeks (311). Dari hasil estimasi diperoleh nilai parameter kekisi 8,408 $\pm 0,040 \AA$. Nilai parameter kekisi ini mendekati nilai parameter referensi kekisi $\mathrm{CoFe}_{2} \mathrm{O}_{4}$ pada keadaan bulk $(8,395 \pm 0,005 \AA)^{[7]}$. Indikasi terbentuknya fasa $\mathrm{CoFe}_{2} \mathrm{O}_{4}$ pada sampel ini juga diperkuat dengan munculnya beberapa puncak difraksi lain dengan indeks miller (220), (400), (511), dan (440). Ketika penambahan PEG ke dalam sampel $\mathrm{CoFe}_{2} \mathrm{O}_{4}$ terbentuk fasa $\alpha-\mathrm{Fe}_{2} \mathrm{O}_{3}$ (hematit), $\alpha-\mathrm{FeO}(\mathrm{OH})$, dan $\gamma$ $\mathrm{FeO}(\mathrm{OH})$. Ukuran partikel dihitung dengan persamaan Scherrer untuk $\mathrm{CoFe}_{2} \mathrm{O}_{4}$ murni dan $\mathrm{CoFe}_{2} \mathrm{O}_{4}+$ PEG-4000 masing-masing $8,8 \mathrm{~nm}$ dan $10,6 \mathrm{~nm}$.

Gambar 2 merupakan hasil uji TEM $\mathrm{CoFe}_{2} \mathrm{O}_{4}$ dan $\mathrm{CoFe}_{2} \mathrm{O}_{4}+$ PEG. Hasil TEM $\mathrm{CoFe}_{2} \mathrm{O}_{4}$ menunjukkan ukuran partikel tidak merata. Distribusi ukuran partikel $\mathrm{CoFe}_{2} \mathrm{O}_{4}$ di bawah $12 \mathrm{~nm}$ dan ukuran diameter rata-rata $8,4 \mathrm{~nm}$ yang konsisten dengan hasil perhitungan dengan persamaan Scherrer pada analisa XRD yaitu $8,8 \mathrm{~nm}$. Garis putus-putus pada pola cincin menunjukkan terjadinya difraksi, sehingga dapat diidentifikasikan indeks millernya berturut-turut: (220), (311), (400), (511), dan (440). Hasil TEM ini sama seperti yang diperoleh melalui XRD.

Gambar 2(b) sampel $\mathrm{CoFe}_{2} \mathrm{O}_{4}+\mathrm{PEG}$ menunjukkan bentuk bulat yang homogen. Ukuran partikel dari $\mathrm{CoFe}-$ ${ }_{2} \mathrm{O}_{4}+\mathrm{PEG}$ lebih besar dibandingkan ukuran partikel $\mathrm{CoFe}-$ ${ }_{2} \mathrm{O}_{4}$. Pada gambar bagian kanan Gambar 2(b) dapat diidentifikasi indeks Miller dari cincin paling dalam sampai terluar: (111), (220), (311), (400), (511), dan (440). Hasil TEM ini menunjukkan bahwa distribusi ukuran partikel paling banyak pada ukuran partikel 10 $\mathrm{nm}$.

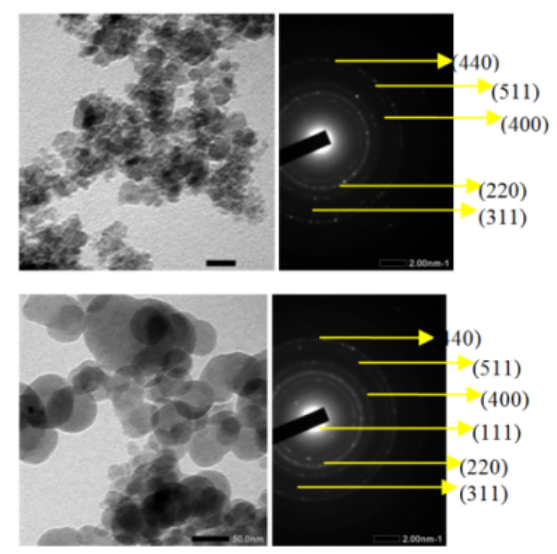

(a)

(b)

Gambar 2. Hasil TEM sampel $\mathrm{CoFe}_{2} \mathrm{O}_{4}$ (b) $\mathrm{CoFe}_{2} \mathrm{O}_{4}$ dilapisi PEG-4000 
Gambar 3 merupakan hasil dari uji FTIR $\mathrm{CoFe}_{2} \mathrm{O}_{4}$, PEG, dan $\mathrm{CoFe}_{2} \mathrm{O}_{4}+\mathrm{PEG}$. Pada puncak serapan 2885,5 $\mathrm{cm}^{-1}$ yang merupakan puncak serapan $\mathrm{CH}_{2}$ stretching asimetris terlihat adanya penurunan ketajaman puncak serapan yang menunjukkan bahwa PEG telah berhasil melapis nanopartikel $\mathrm{CoFe}_{2} \mathrm{O}_{4}$. Pada bilangan gelombang untuk gugus fungsi $\mathrm{M}-\mathrm{O}$ pada sampel yang telah dimodifikasi terdapat pergeseran puncak serapan karena penambahan PEG-4000. Pada grafik $\mathrm{CoFe}_{2} \mathrm{O}_{4}+\mathrm{PEG}$ juga ditemukan puncak baru yaitu pada bilangan gelombang $354,90 \mathrm{~cm}^{-1}$ yang dianalisa sebagai puncak vibrasi ion logam dengan oksigen (M-O). Munculnya puncak baru ini merupakan ikatan antara nanopartikel $\mathrm{CoFe}_{2} \mathrm{O}_{4}$ dengan PEG-4000. Jika dihubungkan dengan hasil analisa XRD, puncak serapan baru ini diprediksi muncul dari vibrasi pada fasa $\alpha$ $\mathrm{FeO}(\mathrm{OH})$ dan $\gamma-\mathrm{FeO}(\mathrm{OH})^{[8]}$.

\section{B. Serapan logam $\mathrm{Cu}, \mathrm{Fe}$ dan $\mathrm{Ni}$}

Gambar 4 menunjukkan limbah cair buatansebelum dan sesudah adsorpsi. Sebelum dilakukan adsorpsi limbah limbah cair buatanberwarna hijau, setelah dilakukan adsorpsi warna pada sampel limbah cair buatanmenjadi jernih. Perubahan warna tersebut mengindikasikan bahwa logam-logam yang sebelumnya terdapat dalam limbah dapat diserap oleh adsorben $\mathrm{CoFe}_{2} \mathrm{O}_{4}$.

\section{Pengaruh Suhu}

Pengaruh suhu terhadap adsorpsi menunjukkan semakin rendahnya kapasitas adsorpsi ketika suhu dinaikkan dikarenakan melemahnya energi ikat antara adsorben dan adsorbat ${ }^{[9]}$.

Pada tabel 1, diperoleh hasil bahwa adsorpsi logam $\mathrm{Fe}$ tidak terpengaruh secara signifikan terhadap perubahan suhu, terlihat dari data untuk logam Fe tidak terdeteksi yang artinya bahwa konsentrasi Fe dalam limbah hasil adsorpsi sangat kecil yang berada di bawah batas deteksi alat $(0,02 \mathrm{ppm})$. Kenaikan suhu juga mengakibatkan penyerapan logam $\mathrm{Ni}$ oleh adsorben naik, namun tidak signifikan. Sementara itu, logam $\mathrm{Cu}$ optimal diadsorpsi pada suhu $60{ }^{\circ} \mathrm{C}$, namun mengalami penurunan setelah suhu dinaikkan menjadi $120{ }^{\circ} \mathrm{C}$. Penurunan adsorpsi ini dikarenakan pada suhu $120{ }^{\circ} \mathrm{C}$ ikatan $\mathrm{Cu}$ dengan adsorben mengalami desorpsi (terlepas kembali) ${ }^{[10]}$. Adsorpsi yang terjadi kemungkinan merupakan adsorpsi fisika sehingga pengaruh suhu sangat berperan dalam proses eksotermis

Tabel 1. Pengaruh suhu terhadap penurunan kadar logam.

\begin{tabular}{crlrrrr}
\hline \multirow{2}{*}{$\begin{array}{c}\text { Para } \\
\text { meter }\end{array}$} & \multirow{2}{*}{$\begin{array}{c}\text { Raw } \\
\text { material }\end{array}$} & \multicolumn{4}{c}{ Suhu } \\
\cline { 3 - 6 } $\mathrm{Cu}$ & 292,144 & Rata-rata(ppm) & 2,72 & 0,87 & 1,19 & 6,17 \\
& & Penurunan (\%) & 99,07 & 99,70 & 99,59 & 98,28 \\
$\mathrm{Fe}$ & 306,240 & Rata-rata(ppm) & Ttd & Ttd & ttd & Ttd \\
& & Penurunan (\%) & 100 & 100 & 100 & 100 \\
$\mathrm{Ni}$ & \multirow{2}{*}{358,940} & Rata-rata(ppm) & 0,34 & 0,23 & 0,19 & 2,45 \\
& & Penurunan(\%) & 99,91 & 99,94 & 99,95 & 99,34 \\
\hline
\end{tabular}

adsorbat. Reaksi adsorpsi terjadi karena adanya gaya Van der Waals dengan keadaan eksotermis. Gaya van Der Waals merupakan ikatan molekul yang lemah dan energi yang dilepaskan relatif rendah sehingga pada suhu yang rendah molekul sudah dapat berikatan dengan adsorben. Suhu meningkat menyebabkan energi dan reaktivitas ion bertambah besar sehingga semakin banyak ion yang mampu melewati tingkat energi untuk melakukan interaksi secara kimia dengan situs-situs di permukaan.

Reaktivitas ion yang semakin besar akan meningkatkan pula difusi ion pada pori-pori adsorben. Sehingga lebih banyak ion yang mampu teradsorpsi pada permukaan seperti yang terlihat pada prosentase adsorpsi di suhu ruang, yakni $60{ }^{\circ} \mathrm{C}$ dan $90{ }^{\circ} \mathrm{C}$. Namun, dengan meningkatnya suhu yang menyebabkan meningkatnya reaktivitas ion ini juga akan dapat mengganggu ikatan yang sudah terbentuk. Hal ini disebabkan lemahnya ikatan Van der Waals sehingga ikatan akan mudah terputus (desorpsi).

\section{Pengaruh Lama Pengadukan}

Waktu pengadukan atau waktu interaksi ion logam dengan adsorben merupakan parameter yang penting untuk mengetahui kecepatan reaksi adsorpsi. Tabel 2 menunjukkan pengaruh dari lama pengadukan terhadap adsorpsi ion logam. Penyerapan terbesar terjadi pada logam Fe. Hal ini menunjukkan bahwa logam Fe lebih cepat diserap oleh adsorben daripada $\mathrm{Cu}$ dan $\mathrm{Ni}$ yang dimungkinkan karena afinitas logam $\mathrm{Fe}$ terhadap adsorben lebih tinggi jika dibandingkan dengan $\mathrm{Ni}$ dan $\mathrm{Cu}$. Penyerapan logam $\mathrm{Cu}$ mengalami penurunan pada waktu pengadukan 3 jam dan naik lagi pada waktu pengadukan 5 jam.

Penurunan adsorpsi logam $\mathrm{Cu}$ pada 3 jam diindikasikan penyerapan logam $\mathrm{Cu}$ mengalami desorpsi atau terlepas kembali dari adsorben yang disebabkan oleh lemahnya interaksi yang terjadi antar ion logam $\mathrm{Cu}$ dengan adsorben dan logam $\mathrm{Cu}$ ini juga harus berkompetisi dengan logam $\mathrm{Fe}$ dan $\mathrm{Ni}$ untuk terikat pada permukaan adsorben. Namun pada waktu pengadukan 5 jam adsorpsi naik lagi menjadi 99,55\% diindikasikan karena pengadukan yang terus menerus dengan bertambahnya waktu mengakibatkan meningkanya reaktivitas ion dan waktu kontak dengan adsorben semakin lama sehingga memberikan kesempatan lebih banyak terbentuk ikatan $\mathrm{Cu}$ dengan adsorben.

Tabel 2. Pengaruh lama pengadukan terhadap penurunan kadar logam.

\begin{tabular}{|c|c|c|c|c|c|}
\hline \multirow{2}{*}{ Parameter } & \multirow{2}{*}{$\begin{array}{c}\text { Raw } \\
\text { material }\end{array}$} & & \multicolumn{3}{|c|}{ Lama pengadukan } \\
\hline & & & 1 jam & 3 jam & 5 jam \\
\hline \multirow{2}{*}{$\mathrm{Cu}$} & \multirow{2}{*}{292,144} & Rata-rata(ppm) & 1,64 & 2,72 & 1,30 \\
\hline & & Penurunan $(\%)$ & 99,44 & 99,07 & 99,55 \\
\hline \multirow{2}{*}{$\mathrm{Fe}$} & \multirow{2}{*}{306,240} & Rata-rata(ppm) & ttd & $\mathrm{Ttd}$ & $\operatorname{ttd}$ \\
\hline & & Penurunan $(\%)$ & 100 & 100 & 100 \\
\hline \multirow{2}{*}{$\mathrm{Ni}$} & \multirow{2}{*}{358,940} & Rata-rata(ppm) & 2,13 & 0,34 & 0,52 \\
\hline & & Penurunan(\%) & 99,41 & 99,91 & 99,85 \\
\hline
\end{tabular}




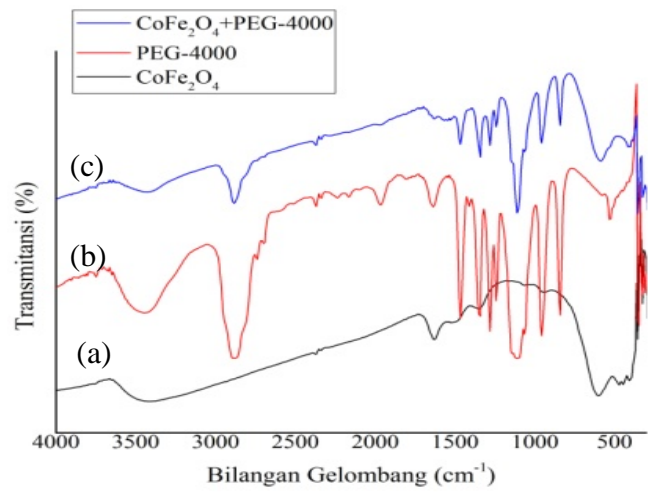

Gambar 3. Spektrum FTIR (a) $\mathrm{CoFe}_{2} \mathrm{O}_{4}$, (b) PEG-4000,dan (c) $\mathrm{CoFe}_{2} \mathrm{O}_{4}$ yang dilapisi PEG-4000.

Tabel 3. Pengaruh readsorpsi

\begin{tabular}{cclrr}
\hline \multirow{2}{*}{ Parameter } & Raw & & \multicolumn{2}{c}{ Adsorpsi } \\
\cline { 3 - 5 } material & & Pertama & Kedua \\
\hline \multirow{2}{*}{$\mathrm{Cu}$} & \multirow{2}{*}{292,144} & Rata-rata(ppm) & 2,73 & Ttd \\
& & Penurunan(\%) & 99,07 & 100,00 \\
$\mathrm{Fe}$ & \multirow{2}{*}{306,240} & Rata-rata(ppm) & ttd & Ttd \\
& & Penurunan(\%) & 100 & 100 \\
$\mathrm{Ni}$ & \multirow{2}{*}{358,940} & Rata-rata(ppm) & 0,34 & $\mathrm{Ttd}$ \\
& & Penurunan(\%) & 99,91 & 100,00 \\
\hline
\end{tabular}

Penurunan adsorpsi logam $\mathrm{Cu}$ pada 3 jam diindikasikan penyerapan logam $\mathrm{Cu}$ mengalami desorpsi atau terlepas kembali dari adsorben yang disebabkan oleh lemahnya interaksi yang terjadi antar logam $\mathrm{Cu}$ dengan adsorben dan $\mathrm{Cu}$ ini juga harus berkompetisi dengan logam $\mathrm{Fe}$ dan Ni untuk terikat pada adsorben. Namun saat pengadukan 5 jam adsorpsi naik menjadi 99,55\% diindikasikan karena pengadukan yang terus menerus dengan bertambahnya waktu akan meningkatnya reaktivitas ion dan waktu kontak dengan adsorben semakin lama sehingga memberikan kesempatan lebih banyak terbentuk ikatan $\mathrm{Cu}$ dengan adsorben.

\section{Pengaruh Readsorpsi}

Readsorpsi merupakan proses adsorpsi berulang. Pada penelitian ini adsorpsi dilakukan pada $\mathrm{pH} 9$ dan waktu pengadukan 3 jam.

Pada proses adsorpsi pertama, kadar logam $\mathrm{Cu}, \mathrm{Fe}$, dan $\mathrm{Ni}$ berhasil diturunkan hingga 2,72 ppm, 0,0 ppm, dan $0,34 \mathrm{ppm}$ pada proses adsorpsi pertama. Sedangkan pada adsorpsi kedua, seluruh ion logam teradsorpsi mencapai $100 \%$. Hal tersebut karena ion-ion logam $\mathrm{Cu}, \mathrm{Fe}$, dan $\mathrm{Ni}$ yang tidak teradsorpsi pada proses adsorpsi pertama akan diadsorpsi oleh adsorben $\mathrm{CoFe}_{2} \mathrm{O}_{4}$ baru yang masih memiliki banyak site aktif pada proses adsorpsi kedua. Hasil penelitian ini memberikan informasi bahwa semakin banyak proses pengulangan, penurunan kadar logam yang terlarut semakin besar.

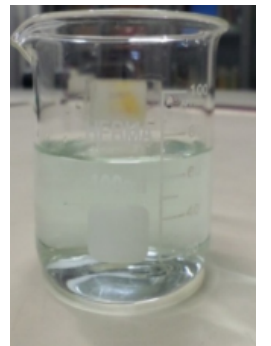

(a)

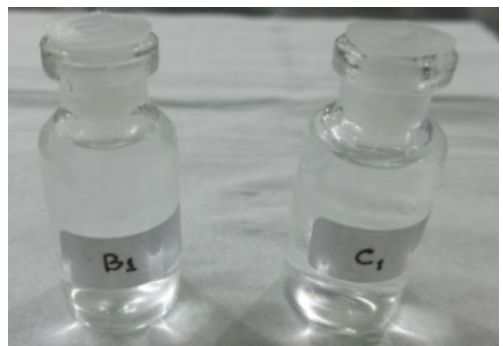

(b)
Gambar 4. (a) Limbah cair buatan sebelum proses adsorpsi dan (b) setelah proses adsorpsi.

Tabel 4. Pengaruh pelapisan adsorben dengan PEG

\begin{tabular}{|c|c|c|c|c|}
\hline \multirow[b]{2}{*}{$\begin{array}{l}\text { Para } \\
\text { meter }\end{array}$} & \multirow{2}{*}{$\begin{array}{c}\text { Raw } \\
\text { material }\end{array}$} & & \multicolumn{2}{|c|}{ Adsorben } \\
\hline & & & $\mathrm{CoFe}_{2} \mathrm{O}_{4}$ & $\begin{array}{l}\mathrm{CoFe}_{2} \mathrm{O}_{4}+ \\
\text { PEG-4000 }\end{array}$ \\
\hline \multirow{2}{*}{$\mathrm{Cu}$} & \multirow{2}{*}{338,365} & Rata-rata(ppm) & 2,73 & 8,47 \\
\hline & & Penurunan(\%) & 99,07 & 97,50 \\
\hline \multirow{2}{*}{$\mathrm{Fe}$} & \multirow{2}{*}{276,729} & Rata-rata(ppm) & ttd & Ttd \\
\hline & & Penurunan(\%) & 100 & 100 \\
\hline \multirow{2}{*}{$\mathrm{Ni}$} & \multirow{2}{*}{350,581} & Rata-rata(ppm) & 0,34 & 1,31 \\
\hline & & Penurunan $(\%)$ & 99,91 & 99,63 \\
\hline
\end{tabular}

\section{Pengaruh Pelapisan Adsorben dengan PEG-4000}

PEG digunakan untuk membungkus atau melapisi adsorben $\mathrm{CoFe}_{2} \mathrm{O}_{4}$ sehingga tidak mudah teroksidasi. Selain itu PEG juga berfungsi mengontrol ukuran dan struktur pori dari partikel. Namun ukuran partikel setelah dilapisi PEG (10,2 nm) menjadi lebih besar dibandingkan dengan $\mathrm{CoFe}_{2} \mathrm{O}_{4}$ tanpa dilapisi PEG $(8,6 \mathrm{~nm})$. Ukuran partikel adsorben terkait dengan luas permukaan adsorben. Adsorben dengan ukuran partikel yang kecil memiliki luas permukaan kontak yang lebih besar dibandingkan ukuran partikel yang besar pada volume yang sama sehingga lebih banyak logam yang diadsorpsi oleh permukaan adsorben. Oleh karena itu, $\mathrm{CoFe}_{2} \mathrm{O}_{4}$ yang dilapisi dengan PEG mengadsorpsi ion logam tidak lebih baik dibandingkan dengan $\mathrm{CoFe}_{2} \mathrm{O}_{4}$ yang tidak dilapisi PEG (Tabel 4).

\section{KESIMPULAN}

Nanopartikel $\mathrm{CoFe}_{2} \mathrm{O}_{4}$ secara efektif dapat digunakan sebagai adsorben untuk menurunkan kadar ion $\operatorname{logam} \mathrm{Cu}$, $\mathrm{Fe}$, dan $\mathrm{Ni}$ dalam limbah cair buatan cair. Prosentase penurunan kadar ion logam tidak terpengaruh secara signifikan oleh perubahan suhu dan lama pengadukan. Proses pengulangan (readsorbsi) mampu meningkatkan adsorpsi ion logam hingga $100 \%$. Namun, pelapisan dengan PEG-4000 menurunkan kemampuan nanopartikel $\mathrm{CoFe}_{2} \mathrm{O}_{4}$ dalam mengadsorpsi ion logam hal ini terkait dengan ukuran partikel dari adsorben. 


\section{UCAPAN TERIMA KASIH}

1. Nano-Fabrication Consortium of Nagoya University, Ministry of Education, Culture, Sports, Science and Technology (MEXT) Nano-Project Platform, Japan, 2012-1017.

2. Hibah Penelitian Kompetisi (Hikom), Dikti, Kementrian Pendidikan Nasional, 2015-2016.

\section{PUSTAKA}

[1] F. Fu, Q. Wang, Removal of heavy metal ions from wastewaters: A review, Journal of Environmental Management, 92, 2011, 407-418.

[2] Coey, J.M.D., Magnetism and Magnetic Materials, United States of America, Cambridge University Press, 2009.

[3] Y., Huang, W., Weiqing, F., Qiming dan F., Faqin, Preparation of Magnetic Clinoptilolite/CoFe ${ }_{2} \mathrm{O}_{4}$ Composites for Removal of $\mathrm{Sr}^{2+}$ from Aqueous Solution: Kinetic, Equilibrium, and Thermodynamic Studies, Journal of Saudi Chemical Society, 2013.

[4] A, Dey., R., Singh, dan M., Purkait, Cobalt Ferrite Nanoparticles Aggregated Schwertmannite: A Novel Adsorbent for The Efficient Removal of Arsenic, Jurnal of Water Process Engineering, 3, 2014, 1-9.

[5] Y., Zhang, Y., Liangguo, X., Weiying, G., Xiaoyao, C., Limei dan G.,Liang, Asorption of $\mathrm{Pb}$ (II) an $\mathrm{Hg}$ (II) from Aqueous Solution Using Magnetic $\mathrm{CoFe}_{2} \mathrm{O}_{4}$-Reduced Graphene Oxide, Journal of Molecular Liquids, Elsevier, 191, 2014,177-182.

[6] J., Wei, J., Xiaofei, L., Qi, L., Zhanshaung, L., Lianhe, dan W., Jun, Magnetic Separation of Uranium by $\mathrm{CoFe}_{2} \mathrm{O}_{4}$ Hollow Spheres, Chemical Engineering Journal, Elsevier, 241,2014,228-234.

[7] Y., Kim, D., Kim, dan Lee, C.S., Synthesis and Characterization of $\mathrm{CoFe}_{2} \mathrm{O}_{4}$ Magnetic Nanoparticles Prepared by Temperature-controlled Coprecipitation Method, Physica B,337,2003,42-51.

[8] De Palma, R., Peeters, S., Van Bael, M.J.., Van den Rul, H., Bonroy, K., Laureyn, W., Mullens, J., Borghs, G., dan Maes, G.,Silane Ligand Exchange to Make Hydrophobic Superparamagnetic Nanoparticles water Dispersible, Chemistry of Materials, 19, 2010, 1821-1831.

[9] L., Zhao, X., ,Li, Q., Zhao, Z., Qu, D., Yuan, X., Hu, dan G., Chen, Synthesis, Characterization and adsorptive Performance of $\mathrm{MgFe} 2 \mathrm{O} 4$ Nanosphere for So2 removal, Journal of Hazardous Materials, 184,2010,704-709.

[10] Rahmi, Aplicationn of Modified Khitosan for Asorben Ionic $\mathrm{Cu}^{2+}$ Metal in Diesel Oil, Natural Jurnal, Vol 9, No.2, 2009. 